\title{
MEMBANGUN LOYALITAS PASIEN DENGAN PENANGANAN KOMPLAIN DALAM MEWUJUDKAN MUTU PELAYANAN DI RSUD SURAKARTA
}

\section{Influence of Service Quality and Complaints Handling Patient Loyalty Through Patient Satisfactionat the General Hospital RSUD surakarta of district}

\author{
Purwito Kesdu AC ${ }^{1}$, Joko Sekti Riyadi ${ }^{2}$ \\ purwito.aub@gmail.com
}

\begin{abstract}
ABSTRAKSI
Penelitian ini bertujuan untuk mengetahui pengaruh kualitas pelayanan, penanganan komplain terhadap kepuasan dan dampaknya pada perilaku pasien di RSUD Surakarta. Pengambilan sampel dalam penelitian ini dengan menggunakan teknik Random sampling. Jumlah sampel yang diambil dalam penelitian ini adalah sebanyak 85 responden yang merupakan pasien RSUD Surakarta. Alat analisis yang dipakai adalah uji instrumen penelitian, u ji linearitas, analisis jalur dan regresi dengan uji $t$, uji $F$ dan Uji $R^{2}$. Hasil Uji $t$ menunjukkan bahwa kualitas pelayanan, penanganan komplain berpengaruh positif signifikan terhadap kepuasan pasien. Dan kualitas pelayanan, penanganan komplain dan kepuasan berpengaruh positif signifikan terhadap loyalitas pasien. Hasil pengaruh langsung dan tidak langsung dapat disimpulkan bahwa variabel kepuasan sebagai variabel intervening kualitas pelayanan dan penanganan komplain adalah tidak efektif, dan lebih efektif kualitas pelayanan dan penanganan komplain berpengaruh secara langsung terhadap loyalitas pasien RSUD Surakarta. Sedangkan untuk Jalur langsung kualitas pelayanan terhadap loyalitas merupakan jalur yang paling dominan dan paling efektif meningkatkan loyalitas, karena mempunyai nilai koefisien regresi yang paling tinggi.

Kata kunci : kualitas pelayanan, penanganan komplain, kepuasan dan loyalitas
\end{abstract}

\section{ABSTRACT}

This study aims to determine the effect of service quality, handling complaints against satisfaction and their impact on the behavior of patients in Surakarta Hospital. Sampling in this study using Random sampling technique. The number of samples taken in this study were 85 respondents who were patients in Surakarta Hospital. The analytical tool used is a research instrument test, ie linearity, path analysis and regression with $t$ test, $F$ test and $R 2$ test. The results of the $t$ test show that the quality of service, handling complaints has a significant positive effect on patient satisfaction. And the quality of service, handling complaints and satisfaction have a significant positive effect on patient loyalty. The results of direct and indirect influence can be concluded that the satisfaction variable as an intervening variable in the quality of service and complaint handling is ineffective, and more effective the quality of service and handling complaints directly affects the loyalty of patients in Surakarta Hospital. While for the direct path of service quality to loyalty is the most dominant and most effective path to increase loyalty, because it has the highest regression coefficient value.

Keywords: service quality, handling complaints, satisfaction and loyalty

\section{PENDAHULUAN}

Perkembangan dalam kemajuan suatu Bangsa ditandai dengan muncul dan tumbuhnya berbagai pelayanan, baik pelayanan produk barang atau produk jasa yang masing-masing menjalankan usaha yang tidak sama. Pelayanan yang dijalankan oleh RSUD Surakarta tersebut sangat membantu dalam menciptakan kesejahteraan pasien. Dalam rangka penyelenggaraan pelayanan kesehatan RSUD Surakarta merasa bertanggung jawab yang harus diikuti dengan pengetahuan. Sebagai penyelenggara pelayanan tersebut dilakukan berdasarkan prinsip- prinsip transparasi partisipasi dan akuntanbilitas. Tujuan dari penyelenggaraan pelayanan kesehatan kepada masyarakat RSUD Surakarta mempunyai kewenangan. Kebebasan untuk 
membentuk dan melaksanakan kebijakan menurut prakata maupun aspirasi pasien kecuali kewenangankewenangan yang tetap melekat pada pemerintah pusat (Adisubrata, 2011: 10). Memberikan pelayanan publik yang baik dan professional hanya biasa dilakukan dengan di dukung dengan sistem akuntabilitas kebijakan yang biasa diambil oleh segenap pasien daerah yang bersangkutan. Di era globalisasi kualitas dipandang sebagai salah satu hal penting untuk mencapai keunggulan kompetitif dengan pesaing maupun pelayanan jasa yang lain. Kualitas merupakan penentu dalam pemilihan produk atau jasa bagi pasien.

RSUD Surakarta yang berbasis pada asas kepercayaan yang menuntut makin mengoptimalkan pelayanan kepada pasien. Hal ini dilakukan agar kepuasan pasien tetap terjaga yang artinya pasien merasa puas apabila kebutuhannya terpenuhi, puas karena pelayanan yang diberikan oleh RSUD Surakarta. RSUD Surakarta harus menyiapkan berbagai perangkat yang dibutuhkan agar pelayanan yang diberikan kepada pasien dapat memenuhi syarat. Perangkat yang dibutuhkan pemerintah tersebut, seperti kebijakan mengenai jenis pelayanan, organisasi, personil, dana yang cukup, peralatan yang memadai dan berbagai perangkat lainnya yang secara integratif akan menciptakan sistem pelayanan yang berkualitas.

Dalam era globalisasi dewasa ini salah satu tantangan besar yang dihadapi oleh pemerintah khususnya pemerintah daerah adalah bagaimanamenampilkan aparatur yang profesional, memiliki etos kerja yang tinggi, keunggulan kompetitif dan kemampuan memegang teguh etika birokrasi dalam menjalankan tugas dan fungsinya dan memenuhi aspirasi pasien. Tantangan tersebut merupakan hal yang beralasan mengingat secara empiris pasien di daerah menginginkan agar aparat pemerintah dalam menjalankan tugas-tugasnya dapat bekerja secara maksimal yang akhirnya dapat memberikan pelayanan yang terbaik bagi pasien. Untuk dapat menyelenggarakan pemerintahan yang baik dituntut aparatur pemerintah yang professional, hal ini merupakan prasyarat dalam meningkatkan mutu penyelenggaraan dan kualitas pelayanan yang akan diberikan kepada pasien.

Salah satu harapan pasien selaku pasien pelayanan adalah menginginkan pelayanan yang adil dan merata. Bentuk pelayanan yang adil dan merata, hanya dimungkinkan oleh kesiapan psikologis birokat pemerintah yang senantiasa menyesuaikan diri dengan perubahan sosial (Social change) dan dinamika pasien sebagai sasaran pelayanannya. Tugas pokok Pemerintah pada hakekatnya adalah memberikan pelayanan kepada pasien dalam rangka meningkatkan kesejahteraan pasien, sehingga pasien puas dan loyal terhadap pemerintah.

Terciptanya pelayanan yang baik pada hakikatnya akan menimbulkan kepuasan bagi pihak yang mendapat pelayanan. Pada dasarnya kepuasan merupakan hal yang bersifat pribadi. Setiap individu akan merasakan tingkat kepuasan yang berbeda- beda sesuai dengan sistem nilai yang berlaku pada dirinya. Hal ini disebabkan karena adanya perbedaan individu. Kepuasan dalam diri individu mempunyai peranan penting dalam rangka mendukung tercapainya tujuan RS RSUD Surakarta. RSUD Surakarta sebagai organisasi pelaksana pelayanan di wilayah kerjanya harus meningkatkan kualitas pelayanan kepada pasien, karena pada hakikatnya kualitas ditentukan hanya oleh pasien. Salah satu cara untuk meningkatkan kualitas pelayanan adalah dengan memenuhi harapan pasien dengan cara meningkatkan mutu pelayanan. Rasa puas orang yang memerlukan kualitas pelayanan bisa diartikan dengan membandingkan bagaimana pandangan antara pelayanan yang diterima dengan harapan pelayanan yang diharapkan. Sementara itu harapan pasien dapat terbentuk berdasarkan pengalaman maupun informasi.

Keluaran yang diharapkan RS RSUD Surakarta dengan mengedepankan kualitas layanan dan penanganan komplain adalah kepuasan pasien. Kepuasan pasien merupakan sebuah penilaian dari pasien bahwa mereka menyukai atas produk yang ditawarkan oleh RSUD Surakarta . Jika kembali pada pemahaman akan konsep pemasaran, maka jelas sekali yang menjadi tujuan setiap aktivitas pemasaran RSUD Surakarta adalah kepuasan pasien. Sehingga apabila pasien merasa puas dengan produk yang dihasilkan dan ditawarkan oleh RSUD kepada pasien mendapat pengakuan atas kinerja (kualitas layanan) dan hal-hal pendukung lain (Hackman, Herbig, Paul, John Milewicz and Jim Golden., 2006:107).

Rumah Sakit RSUD Surakarta dalam pemasaran jasa masih kurang optimal, dan masih banyak ditemukan suatu permasalahan di RSUD hal ini dapat dilihat masih banyaknya pasien yang komplain atas pelayanan yang diberikan, kualitas pelayanan yang ada di RSUD Surakarta masih belum sesuai dengan 
harapan pasien, penanganan komplain masih rendah dan belum diminati oleh pasien, kepuasan pasien di RSUD Surakarta sangat rendah, sehingga loyalitas pasien dirasakan masih kurang, sehingga perlu adanya peningkatan. Konsep kepuasan pasien merupakan hasil dari keberhasilan penyedia produk memenuhi harapan pasien secara definitif mempengaruhi perubahan sikap, pembelian ulang dan loyalitas. Ketiga hal ini merupakan hasil yang diharapkan dari keseluruhan aktivitas pemasaran (Webster, 2011:108). Namun penelitian mengenai kedua konsep diatas pada pemasaran jasa masih jarang ditemukan, dan masih banyak ditemukan suatu permasalahan di RSUD Surakarta , kualitas pelayanan yang ada masih belum sesuai dengan harapan pasien, penanganan komplain masih rendah dan belum diminati oleh pasien, kepuasan pasien di RSUD Surakarta sangat rendah dan loyalitas pasien perlu adanya peningkatan.

Berangkat dari fenomena dan pemikiran- pemikiran di atas, maka diperlukan penelitian berkenaan dengan pengaruh sistem penyampaian jasa tehadap kualitas pelayanan, penanganan komplain terhadap dan loyalitas pasien. Untuk itulah kiranya penulis tertarik untuk melakukan penelitian mengenai "Membangun Loyalitas Pasien Dengan Penanganan Komplain Dalam Mewujudkan Mutu Pelayanan di RSUD Surakarta".

\section{METODE}

Variabel yang digunakan dalam penelitian ini terdiri dari variabel independen $(\mathrm{X})$, variabel intervening (e) dan variabel dependen $(\mathrm{Y})$. Variabel independen terdiri dari kualitas $\left(\mathrm{X}_{1}\right)$, penanganan komplain $\left(\mathrm{X}_{2}\right)$, sedangkan variabel intervening adalah kepuasan pasien dan variabel dependen adalah loyalitas pasien (Y). Populasi dalam penelitian ini adalah pasien di RSUD Surakarta sejumlah 850 pasien bulan Januari-Maret 2018. Dan sampel yang diambil dalam penelitian ini adalah sebesar $10 \%$ dari populasi yaitu sebesar 85 pasien. Dengan Teknik random sampling.

Teknik analisis statistik yang digunakan dalam penelitian ini adalah jalur (path analisis). Analisis regresi linear berganda digunakan untuk menganalisa pengaruh beberapa variabel bebas atau independen variabel $(\mathrm{X})$ terhadap satu variabel tidak bebas atau dependen variabel (Y) sebagai berikut:.

Keterangan:

$$
\begin{aligned}
& Y_{1}=b_{1} X_{1}+b_{2} X_{2}+e_{1} \\
& Y_{2}=b_{1} X_{1}+b_{2} X_{2}+b_{3} X_{3}+e_{2}
\end{aligned}
$$

$\mathrm{Y}_{1} / \mathrm{X}_{3}=$ Kepuasan

$\mathrm{Y}_{2} \quad=$ Loyalitas Pasien

$\mathrm{X}_{1} \quad=$ Kualitas

$\mathrm{X}_{2} \quad=$ Penanganan komplain

$\mathrm{b}_{1}, \mathrm{~b}_{2}, \mathrm{~b}_{3}=$ Koefisien regresi

$\mathrm{e}_{1}, \mathrm{e}_{2}, \mathrm{e}_{3}$ 


\section{HASIL PENELITIAN}

Tabel IV.11.

Hasil Regresi Persamaan Pertama

\begin{tabular}{|c|c|c|c|c|c|}
\hline & Coeffic & & & & \\
\hline \multirow[b]{2}{*}{ Model } & \multicolumn{2}{|c|}{$\begin{array}{l}\text { Unstandardized } \\
\text { Coefficients }\end{array}$} & \multirow{2}{*}{\begin{tabular}{|c}
$\begin{array}{l}\text { Standardized } \\
\text { Coefficients }\end{array}$ \\
Beta \\
\end{tabular}} & \multirow[b]{2}{*}{$\mathrm{t}$} & \multirow[b]{2}{*}{ Sig } \\
\hline & $B$ & Std. Error & & & \\
\hline $\begin{array}{ll}1 & \text { (Constant) }\end{array}$ & 7,197 & 1,353 & & 5,321 & .000 \\
\hline Kualitas Pelayanan & .478 & .072 & 608 & 6,610 & .000 \\
\hline Penanganan komplai & .170 & .080 & .196 & 2,128 & .036 \\
\hline
\end{tabular}

Tabel IV.12.

Hasil Regresi Persamaan Kedua

Coefficients $^{\mathrm{a}}$

\begin{tabular}{|c|c|c|c|c|c|}
\hline \multirow[b]{2}{*}{ Model } & \multicolumn{2}{|c|}{$\begin{array}{l}\text { Unstandardized } \\
\text { Coefficients }\end{array}$} & \multirow{2}{*}{\begin{tabular}{|r|}
$\begin{array}{l}\text { Standardized } \\
\text { Coefficients }\end{array}$ \\
Beta \\
\end{tabular}} & \multirow[b]{2}{*}{$t$} & \multirow[b]{2}{*}{ Sig. } \\
\hline & B & Std. Error & & & \\
\hline \multirow{4}{*}{$\begin{array}{l}\text { (Constant) } \\
\text { Kualitas Pelayanan Penanganan } \\
\text { komplai Kepuasan }\end{array}$} & 5,927 & 1,349 & & 4,395 &, 000 \\
\hline & 208 & .077 & 289 & 2,700 & .008 \\
\hline & 203 & .071 & 254 & 2,868 & .005 \\
\hline & .324 & . & ,353 & 3,409 & $\mid, 001$ \\
\hline
\end{tabular}

Tabel IV.13

Hasil Uji F Persamaan 1

\begin{tabular}{|c|c|c|c|c|c|c|}
\hline \multicolumn{7}{|c|}{ ANOVAP } \\
\hline Model & & $\begin{array}{l}\text { Sum of } \\
\text { Squares }\end{array}$ & df & Mean Square & $\mathrm{F}$ & \\
\hline \multirow{3}{*}{1} & Regression & 241,296 & 2 & 120,648 & 49,836 &, $000^{a}$ \\
\hline & Residual & 198,515 & 82 & 2,421 & & \\
\hline & Total & 439,812 & 84 & & & \\
\hline
\end{tabular}

Tabel IV.14

Hasil Uji F Persamaan 2

\begin{tabular}{|c|c|c|c|c|c|c|}
\hline \multicolumn{7}{|c|}{ ANOVA } \\
\hline Model & & $\begin{array}{l}\text { Sum of } \\
\text { Squares }\end{array}$ & $d f$ & Mean Square & $\mathrm{F}$ & \\
\hline \multirow[t]{3}{*}{1} & Regression & 223,878 & 3 & 74,626 & 41,724 &, $000^{a}$ \\
\hline & Residual & 144,875 & 81 & 1,789 & & \\
\hline & Total & 368,753 & 84 & & & \\
\hline
\end{tabular}
Dependent Variable: Loyalitas

Tabel IV.15

Koefisien Determinan Persamaan $1\left(\mathrm{R}^{2}\right)$

Model Summary
\begin{tabular}{|l|c|l|l|l|}
\hline Model & R & R Square & $\begin{array}{l}\text { Adjusted } \\
\text { R Square }\end{array}$ & $\begin{array}{l}\text { Std. Error of the } \\
\text { Estimate }\end{array}$ \\
\hline 1 & \multicolumn{2}{|c|}{$, 747,549$} &, 538 & 1,556 \\
\hline
\end{tabular}

a. Predictors: (Constant), Penanganan komplai, Kualitas Pelayanan

Tabel IV.16

Koefisien Determinan Persamaan $2\left(\mathrm{R}^{2}\right)$

\begin{tabular}{|l|r|r|r|r|}
\multicolumn{7}{|c|}{ Model Summary } \\
\hline Model & $\mathrm{R}$ & R Square & $\begin{array}{c}\text { Adjusted } \\
\text { R Square }\end{array}$ & $\begin{array}{r}\text { Std. Error of } \\
\text { the Estimate }\end{array}$ \\
\hline 1 &, $779^{\mathrm{a}}$ &, 607 &, 593 & 1,337 \\
\hline
\end{tabular}

a. Predictors: (Constant), Kepuasan, Penanganan komplai, Kualitas Pelayanan

b. Dependent Variable: Loyalitas
Tabel IV.17

Koefisien Korelasi

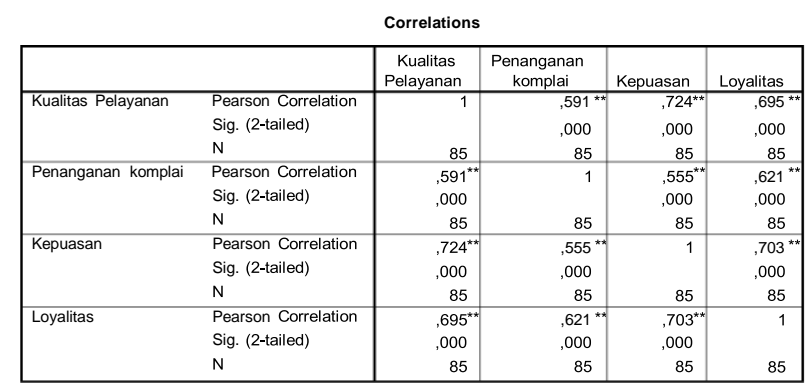

Berdasarkan hasil analisa jalur dapat diperoleh hasil sbb:

Persamaan 1 yaitu :

$\mathrm{Y}_{1}=0,608 \mathrm{X}_{1}+0,196 \mathrm{X}_{2}$

Keterangan:

1. Kualitas pelayanan berpengaruh positif terhadap kepuasan pasien.

2. Penanganan komplain berpengaruh positif terhadap kepuasan pasien

Persamaan 2 yaitu :

$\mathrm{Y}_{2}=0,289 \mathrm{X}_{1}+0,254 \mathrm{X}_{2}+0,353 \mathrm{X}_{3}$

Keterangan:

1. Kualitas pelayanan berpengaruh positif terhadap loyalitas Pasien

2. Penanganan komplain berpengaruh positif terhadap loyalitas Pasien.

3. Kepuasan berpengaruh positif terhadap loyalitas Pasien
Model Hasil Analisis:

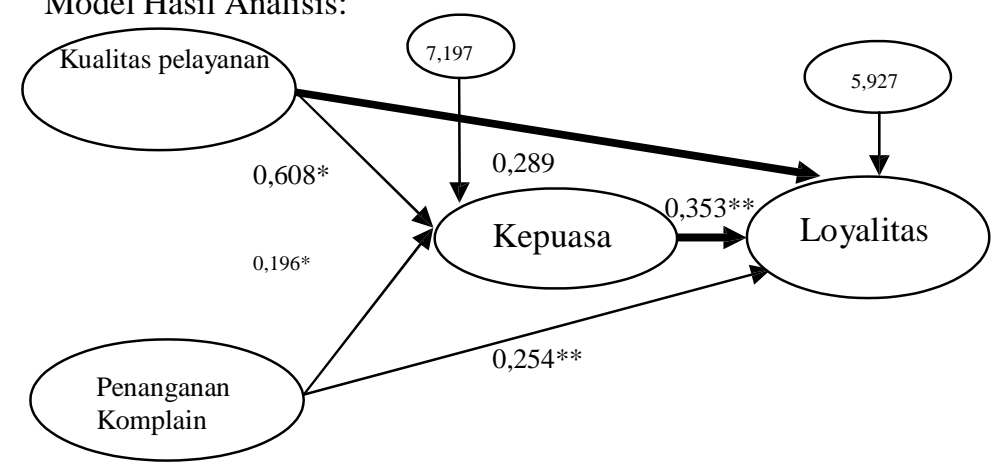




\section{PEMBAHASAN}

1. Pengaruh Kualitas pelayanan Terhadap Loyalitas Hasil analisis jalur menunjukkan bahwa penggunaan variabel intervening kepuasan dalam rangka peningkatan loyalitas Pasien di RSUD Surakarta, untuk variabel kualitas pelayanan adalah tidak efektif, karena pengaruh tidak langsung lebih kecil dari pada pengaruh langsung. Hal ini berarti, untuk meningkatkan loyalitas Pasien di RSUD Surakarta sebaiknya menggunakan variabel kualitas pelayanan secara langsung.

Hasil ini sesuai dengan penelitian yang dilakukan oleh Dwi Dan Febrina, (2010) yang menyatakan bahwa kualitas pelayanan berpengaruh positif dan signifikan terhadap loyalitas.

Hal ini dapat dilakukan dalam peningkatan kualitas pelayanan antara lain dengan melihat nilai indikator tertinggi dari uji validitas, langkah-langkahnya adalah dengan cara:

a. Meningkatkan pelayanan di RSUD Surakarta : pelayanan yang diberikan kepada pasien sudah sesuai Standard Operating Procedure (SOP) yang berlaku atau lebih tinggi dari SOP sehingga melebihi harapan pasien, pemberian kenang-kenangan atau souvenir kepada pasien sebagai ucapan terima kasih dan semoga lekas sembuh, hal ini akan menjadi nilai tambah atau value added bagi RSUD Surakarta

b. Meningkatkan kondisi fisik RSUD Surakarta seperti perbaikan dan penambahan gedung baru dan ruang tunggu yang nyaman bagi pasien.

c. Meningkatkan kelengkapan di RSUD Surakarta seperti segera melakukan perbaikan alat-alat medis yang rusak, penggantian atau pembelian peralatan yang using.

Dengan adanya kualitas pelayanan yang baik akan meningkatkan kepuasan pasien, sehingga pasien akan merasakan terlayani dengan baik dan loyalitas akan meningkat di RSUD Surakarta.

2. Pengaruh Penanganan komplain Terhadap Loyalitas

Hasil analisis jalur menunjukkan bahwa penggunaan variabel intervening kepuasan dalam rangka peningkatan loyalitas, untuk variabel penanganan komplain adalah tidak efektif, karena pengaruh tidak langsung lebih kecil dari pada pengaruh langsung. Hal ini berarti, untuk meningkatkan loyalitas Pasien di RSUD Surakarta sebaiknya menggunakan variabel penanganan komplain secara langsung.

Hasil ini sesuai dengan penelitian yang dilakukan oleh Dwi Dan Febrina, (2010) yang menyatakan bahwa penanganan komplain berpengaruh positif dan signifikan terhadap loyalitas.

Hal ini dapat dilakukan dengan peningkatan penanganan komplain pasien antara lain dengan melihat nilai indikator tertinggi dari uji validitas, langkah-langkahnya adalah dengan cara:

a. Penyelesaian masalah yang dihadapi akan diselesaikan RSUD Surakarta secara tepat, misalnya pegawai siap siaga menerima complain dan memberikan solusi.

b. Komplain akan selalu ditanggapi oleh RSUD Surakarta. Misalnya adanya customer service yang selalu siap melayani.

c. RSUD Surakarta menyelesaikan keluhan pasien dengan cepat. Misalnya cepat mengambil tindakan dan memahami apa yang perlu dilakukan.

Dengan adanya penanganan komplain yang baik akan memberikan kepercayaan kepada pasien dan pasien memiliki loyalitas di RSUD Surakarta semakin baik.

\section{PENUTUP}

\section{Simpulan}

1. Kualitas pelayanan berpengaruh positif dan signifikan terhadap kepuasan. Penanganan komplain berpengaruh positif dan tidak signifikan terhadap kepuasan.

2. Kualitas pelayanan dan penanganan komplain berpengaruh positif dan signifikan terhadap loyalitas. kepuasan berpengaruh positif dan signifikan terhadap loyalitas.

3. Hasil uji $\mathrm{F}$ diketahui besarnya nilai $\mathrm{F}=41,724$ signifikansi $0,000<0,05$. Sehingga dapat disimpulkan secara bersama- 
sama variabel kualitas pelayanan, penanganan komplain dan kepuasan berpengaruh signifikan terhadap loyalitas.

4. Hasil perhitungan nilai $\mathrm{R}^{2}$ total sebesar 0,823 dapat diartikan variasi loyalitas Pasien di Rumah Sakit Umum Daerah Surakarta dijelaskan oleh variabel kualitas pelayanan, penanganan komplain dan kepuasan sebesa $82,3 \%$ dan sisanya $17,7 \%$ dijelaskan variabel lain diluar model penelitian sebagai contoh kecepatan pelayanan dan kenyamanan lingkungan.

5. Kesimpulan Pengaruh Langsung dan Tidak Langsung adalah sebagai berikut:

a. Pengaruh langsung kualitas pelayanan terhadap loyalitas menghasilkan nilai lebih besar dibandingkan pengaruh tidak langsung. Sehingga lebih efektif melalui jalur langung.

b. Pengaruh langsung penanganan komplain terhadap loyalitas menghasilkan nilai lebih besar dibandingkan pengaruh tidak langsung. Sehingga lebih efektif melalui jalur langsung.

\section{Saran}

Saran dalam penelitian ini adalah sebagai berikut:

1. Kualitas pelayanan merupakan variabel yang paling dominan dalam meningkatkan loyalitas, untuk itu pihak RSUD Surakarta sebaiknya lebih memperhatikan faktor yang dapat meningkatkan variabel kualitas pelayanan. Misalnya dengan cara: Meningkatkan pelayanan di RSUD Surakarta supaya memadai, meningkatkan kondisi fisik RSUD Surakarta dan meningkatkan kelengkapannya. Dengan adanya kualitas pelayanan yang baik, maka pasien merasa lebih percaya dan merasa puas, serta akan meningkatkan loyalitas pasien.

2. Sebaiknya penanganan komplain lebih ditingkatkan lagi agar hasilnya lebih baik lagi, upaya yang dapat dilakukan antara lain: Penyelesaian masalah yang dihadapi akan diselesaikan secara tepat, Komplain akan selalu ditanggapi dengan baik dan menyelesaikan keluhan pasien dengan cepat.

\section{DAFTAR PUSTAKA}

Adi, Krismanto, 2007, “Analisis Faktor-faktor yang mempengaruhi loyalitas nasabah”, STIE AUB Surakarta.

Anderson, E. and B. Weitz, 2013, "The Use of Arikunto, Suharsini, 2011. Prosedur Penelitian Suatu Pendekatan Praktek Edisi ketiga.

Bolton, Ruth N and james H. Drew, 2011, “A Multi Stage Model of Customers Assessment of Service Quality and Value”, Journal of Consumer Research, Januari, 1-9.

Bontis, Nick and Lorne D.Booker (2007), " The mediating effect of organizational reputation on customer loyalty and service recommendation in banking industry”, Journal Management Decion, Vol.45, No.9 p.1426-1445.

Brown, Stephen W., 2011, “A Multi Stage Model of Customers Assesment of Service Quality and Value”, Journal of Marketing, April, pp. 92-98

Cronin J.Joseph Jr and Steven A. Taylor (2012), "Measuring Service Quality : A reexamination and extension", Journal of Marketing Vol. 56 (July) p.55-68

Dharmesta (2009), Human Resources Management. Tenth Edition. Prentice-Hall.Inc. New Jersey Djarwanto dan Subagyo, Pangestu, 2011: Statistik Induktif, Edisi: 4, Yogyakarta: BPFE.

Dwi Aryani Dan Febrina Rosinta, 2010. Pengaruh Kualitas Layanan Terhadap Kepuasan Pelanggan Dalam Membentuk Loyalitas Pelanggan. Jurnal Ilmu Administrasi Dan Organisasi, Mei-Agus 2010, Hlm. 114- 126. Volume 17, Nomor 2. ISSN 0854-3844

Fandy Tjiptono, 2006, Strategi Pemasaran, Andi ffset, Yogyakarta

Fornell, Claes; Johnson, Michael D ; Anderson, Eugene W ; Cha, Jaesun; Bryant, Barbara Everitt (2006), "The American 
Customer Satisfaction Index : Nature, Purpose, and Findings". Journal of Marketing, 60 (10). (7- 18).

Ghozali, Imam,2009. Aplikasi Analisis Multivariate Dengan Program SPSS Pledges to Build and Sustain Commitment 2010. Analisis Regresi. Jakarta: in Distribution Channel”, Journal of Marketing research 29 (1), p.18-34. Salemba Empat.Gujarati, Damodar. 2010. Ekonometrika Dasar. Erlangga. Jakarta.

Hackman, Herbig, Paul, John Milewicz and Jim Golden., (2006). Achieving The Goals of Multiculturalism and Diversity. In M. Peterson. D. D. Dill. L. Mets, \& Associates (Eds.)”, Planning and Management for A Changing environment (pp.405-431), San Francisco: Jossey-Bass.

Herbig, Paul, John Milewicz and Jim Golden,(2014). “A Model of Reputation Building and Destruction "Journal of Business Research. Vol.31, June 1994, No.1; p.23-31.

Hirschman, 2007, An Assesment Of The Relationship Between Service Quality And Customer Satisfaction In The Formation Of Consumers Purchase Intention”, Journal Of Retailing. Vol 70, No.2, P.163

Istijanto, 2006, Riset Sumber Daya Manusia, Jakarta:PT. Gramedia Pustaka Utama

Juran, J.M., 2011, Quality Control Handbook, New York: Mc. Graw-Hill.

Kotler, Philip. 2008. Marketing management : Analysis, Planing, Implentations, And Control, 9 Th Ed Ed Engle Wood Cliffs, N.J: Prentice Hall International, Inc

Kotler, Philip.(2013), Marketting Management, $11^{\text {th }}$ ed. Upper Saddle River, New Jersey : Prentice Hall, Inc.

Liu, Tsung-Chi and Li Wei Wu (2007), "Customer retention and cross-buying in the banking industry : An Integration of service attributes, satisfaction and trust" Journal of Financial Service Marketing, Vol.12 No.2 p.132-145.

Margaretha M, (2014), "Study Mengenai Loyalitas Nasabah Divisi Asuransi Kumpulan AJB Bumi Putera 1912 (Studi khusus di Jawa Tengah)”, Jurnal Sains Pemasaran Indonesia, Vol III, No.3, Desember 2004. (289-308)

Nyer, 2010. Marketing dan Perlaku Konsumen Mundur Maju, Bandung

Oliver, Richard L. (2007), “Satisfaction : A Behavioral Perspective on the Customer”, McGraw-Hill, New York, NY

Parasuraman, A.,A.Zeithmal, V.,\& L.Berry, L.2007” A conceptual Model of Service Quality and Its Implications for Future Research”, Journal of Marketing, Vol.49 (fall).

Peraturan Presiden Nomor 1 tahun 1995 tentang perbaikan dan peningkatan mutu pelayanan

Prichard, mark P, 2010, “Analyzing the Commitment-Loyalty Link in Service Contexts", Journal of the Academy of Marketing Science 27 (3), p.333-348

Ratminto dan Winarsih, 2005, Manajemen Pelayanan, Pustaka Pelajar, Yogyakarta

Riduwan, 2007, Skala pengukuran Variabel- Variabel Penelitian, Cetakan Ketiga, Alfabeta, Bandung.

Sarwono, Jonathan. 2010. Analisis Jalur Untuk Bisnis dengan SPSS. Penerbit Andi Offset:Yogyakarta

Sekaran U, 2010. Research Methods For Business: A Skill Building Approach Singapore: John Willey dan Sonc, Inc 
Selnes, Fred (2013), "An Examination of the effect of Product Performance on Brand Reputation, Satisfaction and Loyalty", European Journal of Marketing, 27 (9). (19- 35).

Setyo, Budiarto, 2011, "Pengaruh Kualitas Pelayanan terhadap Loyalitas Nasabah dan Reputasi Bank sebagai Variabel Intervening pada Apotek K-24 Jogjakarta” UNS, Surakarta.

Solomon, Michael (2006), Consumer Behavion, $3^{\text {th }}$ edition, McGraw Hill.

Solvang, 2007. Manajemen Pemasaran, Edisi Millenium, Jakarta Prenhalindo

Straus \& Seidel, 2006. An Assesment Of The Relationship Between Service Quality And Customer Satisfaction In The Formation Of Consumers Purchase Intention”, Journal Of Retailing. Vol 70, No.2, P.163

Sugiyono, 2007. Metodologi Penelitian Bisnis,Cetakan Ketujuh, CV. Alpabeta, Bandung.

Supriatna. J (2010). Analisis Multivariate dengan program SPSS. Penerbit Andi Offset:Yogyakarta

Tjiptono, Fandi, 2012, Prinsip-prinsip Total Quality Service (TQS), Andi Offset, Yogyakarta.

Tronvoll, (2007). Produktivitas: Seri Manjemen Sumber Daya Manusia. Jakarta:Alex Media Komputindo

Webster, (2011). Gender and The Relationship Between Perceived Fairness of Pay or Promotion ang Job Satisfaction”, Journal of Applied Psychology, 78 (5) : $744-780$

Zeithaml, V.(2008), Consumer Perceptions of Price, "Quality, and Value : Means End Model and Synthesis of Evidence", Journal of Marketing, Vol 52, July, p.2-22

Zeithaml, Valerie; Berry, Leonard L,; and Parasuraman, A. (2008), "Sevqual: Multiple Item Scale for Measuring Consumer Perceptions of Service Quality", Journal of Retailing, Vol 64 No.1 Spring 